\title{
Competence vs. Identity, Trainees vs. Physicians: How COVID-19 Has Highlighted Role Confusion in Residency Training
}

\author{
Michael A. Shapiro ${ }^{1}$ (D \\ Received: 14 August 2020 / Accepted: 15 October 2020 / Published online: 23 October 2020 \\ (C) Academic Psychiatry 2020
}

The idea for this paper occurred much prior to the COVID-19 pandemic. It was supposed to be a more light-hearted and cheekier take on how residents are the "teenagers" of medical education: almost grown-up, but not quite. The initial intent was to highlight how sometimes residents are viewed as having all the responsibility of being full-grown "adult" doctors, while at other times needing to be protected and/or controlled, enjoying very few privileges of autonomous physicians. The COVID-19 pandemic and response have obviously required swift changes to medical education, but have only further highlighted the mixed messaging and treatment that U.S. residents face during training.

Prior to COVID-19, almost the entirety of this paper was going to be an examination of Erik Erickson's Psychosocial Stages of Development [1], how they relate to educational level, and whether a competency-based evaluation system is sufficient for individuals who are also starting professional identity formation. I will try to do this briefly, then move on to how the current COVID-19 crisis has served to amplify these points for psychiatry residents.

\section{Competence vs. Identity}

Erickson was a child psychoanalyst who developed a list of psychosocial stages, where each stage represents "an unavoidable encounter between the environment and the developing person who is driven by instinctual energy and developing awareness" and results in a corresponding "crisis" that needs to be navigated to resolve the conflict [2]. The crisis or conflict of Erickson's 4th stage is Industry vs. Inferiority, the successful navigation of which leads to the virtue of competence. Competency-based evaluations have become commonplace in medical schools and residency training programs $[3,4]$.

Michael A. Shapiro

mshapiro@ufl.edu

1 University of Florida, College of Medicine, Gainesville, FL, USA
Although this has led to improved consistency across schools and programs on how students and trainees are evaluated, the risk of students and residents not being able to successfully navigate this stage cannot be ignored. Competition among medical school classmates to prove their superiority over each other for coveted positions in medical honor societies and residency positions has led to such detrimental perfectionism and increased stress levels that many medical schools have made the pre-clinical curriculum pass/fail [4]. This sense of competition and fear of inferiority can also mark this stage and partly explains why in typical development, self-esteem takes a dip in middle childhood [5] — and perhaps medical school.

Although residency training still focuses on competency and skill development, residents have already started to embark on the next stage. Residents need to fulfill the expectations that are eventually required to be called a "surgeon," "psychiatrist," or "radiologist." It is not just mastery of skills for a sense of industry, but specific knowledge, attitudes, and values of which they must demonstrate sufficient acquisition in order to fulfill the obligations of the professional identity of their specialty. These attributes are not attained merely by proving superiority over each other, but rather by learning from faculty role models. It would appear residency training also incorporates Erickson's 5th stage, Identity Formation/Cohesion vs. Role Confusion, typically marked in adolescence [1]. This is not an indictment on the lack of emotional maturity of residents and fellows; ample research has already shown that psychological "adolescence" is lasting longer nowadays than in the past [6] and that protracted education can lead to prolonged adolescence and identify formation [7]. Erickson's theories have already been used to describe latelife transitions in medical specialty or transition between practice and academia [2].

\section{Implications for General Residency Training Conditions}

The recognition of residents entering Identity vs. Role Confusion is important regarding how programs evaluate 
and treat residents during residency training, as according to Erickson it is the environment that creates the unavoidable conflict the individual must navigate. Even outside of COVID-19, residents often receive mixed messages about their role in training programs and medical education, highlighting the role confusion of adolescence. Residents are expected to be professionals and develop an altruistic attitude towards their patients and colleagues and are often expected to take on the responsibilities of autonomous physicians. Yet it is also recognized that residents and fellows are a group that requires special protections, such as the Accreditation Council of Graduate Medical Education's (ACGME) 80-h limit [8], as without such protections trainees may be taken advantage of or mistreated [9]. Trainees also lack privileges attained by post-graduate physicians such as financial compensation or ability to negotiate, or flexibility with job requirements, mandatory attendance of didactics, and limited availability of sick leave or child-care. In these aspects, trainees are treated more like children who require special protections and are only granted limited flexibility and autonomy [10].

It is possible, and even likely, that these shifting views are often alternated based on what serves the needs of the environment-training programs and hospital systems - and not necessarily what serves residents needs for growth and development. Residents may be viewed as "physicians" if they are asked to provide clinical services without appropriate supervision or to exceed work hour restrictions, but may be viewed as "trainees" in regard to justifying their low salary, having a limited say in training requirements, and inability to negotiate benefits. Such shifting views may be psychologically detrimental to trainees' professional identity development, as trainees may understand their role as only being of specific use to a training program or hospital, which can vary from place to place. This would add to Role Confusion, rather than Identity Formation/Cohesion.

\section{Implications during COVID-19}

The COVID-19 pandemic has drawn attention to the dual role of residents and fellows as both trainees and physicians [11], and this identity crisis is much more pressing and urgent within the backdrop of the COVID-19 crisis. Three specific issues will be reviewed below, namely (1) the need for protection; (2) professional identity development; and (3) financial compensation.

\section{The Need for Protection}

The American Medical Association (AMA) acknowledges that certain stressors of the pandemic are "unique" to residents due "to their status as employed trainees" [12]. The AMA has noted that many physicians-in-training will be "enlisted" or "deployed" to provide direct patient care during the COVID-
19 pandemic, and they must be protected and have support to maintain safety [13]. These militaristic terms imply that this process may be only semi-voluntary at best, as residents have limitations in autonomy and flexibility [14]. This is as opposed to autonomous physicians, who are allowed to "volunteer" their services [15]. In contrast, residents have feared that their "deployment" may actually lead to delays in their graduation if such work was not felt to contribute to graduation requirements (the AMA has opposed this stance) [12]. Autonomous "volunteers" would inherently have no such risk. A reading of the AMA's Guiding Principles to Protect Residents and Fellows During the COVID-19 Crisis [12] only further serves to highlight how such rights as the ability to raise concerns without recrimination, be actively engaged in response planning, and continue to be paid during sick leave, must be explicitly stated to be given to residents, as if otherwise they may be taken away, similar to the rationale for the United Nations Convention on the Right of the Child [10].

\section{Professional Identity}

The AMA acknowledges that since the start of the COVID-19, residents have been pulled from their primary role to cover other services [16], noting that "many residents are being asked to assume roles that are not a prescribed part of their specialty training" [12]. The AMA goes on to acknowledge that "residents may be compelled to acquire skills on the job that were not an expectation when they began residency" [12]. Although they may be developing other skills necessary to combat the COVID-19 pandemic, and aside from fear of contracting the viral infection, there is implied fear related to developmental delays in their professional identity in their chosen specialty.

On the other end of the spectrum, subspecialty fellows have been asked to serve in attending physician roles in their core disciplines [12]. This could be seen as an early or inappropriate increase in responsibility, although appropriate privilege may be lacking, without a commensurate increase in their compensation and malpractice coverage. Likewise, it is hinted that such activity - likely only made to benefit a specific's program acute needs in this crisis - may lead to said program viewing this service as negatively impacting their completion of the training program, which "must be openly discussed with them" [12]. This is again, Role Confusion, in which a trainee may be simultaneously told they are "competent" enough to act like an attending in service of a program, but in fact a program may use this to harm or delay their professional development in their core discipline, both views that would serve a program at the potential detriment to trainees.

\section{Financial Compensation}

Even prior to the COVID-19, residents in various parts of the U.S.A. had recently banded together to demand more favorable 
financial compensation [17]. Resident salaries are low compared to those of other health care workers, particularly on an hourly basis, and may only equate to approximately $\$ 15$ to $\$ 20 / \mathrm{h}[12]$. Fully autonomous physicians have the ability to negotiate contracts, or quit/resign and look for more competitive positions, not residents. Residents are particularly vulnerable in their negotiating ability as a labor force. Although they are employed health care workers, their dual status as "trainees" makes them dependent upon their employer for their professional development [12]. As such, "their influence over the environment ... is limited," [12] a statement which is often applied to why children and young people also require special protections [10].

Due to being involuntarily reassigned, some residents have demanded hazard pay in order to ensure financial compensation [18]. The AMA has supported such measures, stating residents "should be candidates for hazard pay in a way that is equitable to other health care workers," as well as granted forgiveness and/or forbearance for their student loan debt to ease the financial stress during the COVID-19 crisis [14]. Perhaps it is no coincidence that the very program that attracted the most attention for a pre-COVID residency strike advocating for equal pay and benefits was the same program post-COVID that was lauded by the AMA for protecting its residents during the crisis [19].

\section{Impact of COVID-19 on Psychiatry Trainees}

There have been multiple reports and first-hand accounts of psychiatry residents being re-deployed to cover other services, especially during the initial stages of the pandemic [20-24], including working in ICUs and COVID units $[22,23]$. One program from New York re-deployed all 13 of their PGY-2 psychiatry residents to cover COVID units [20]. A previous publication in this journal detailed the accounts of a rural program that reassigned psychiatry interns to internal medicine services, with one PGY-5 who was also completing a Preventative Medicine program being put in a position to help to coordinate their states' COVID response [21]. Another psychiatry program from New York detailed that of 46 total residents in their program, the first to be re-deployed were interns, assumingly mandatory, and volunteers from the PGY-4 class; when all was said and done, 35 of the 46 residents had experienced re-deployment [23]. One report from a PGY-3 psychiatry resident who "volunteered" to work on an internal medicine COVID unit wrote positively about the experience, and also acknowledged facing their own mortality and having to write their will before being deployed [24].

A common theme appears to be of forced deployment to front-line work of residents in the earlier years of training, interns, and PGY-2s, while upper-levels were initially afforded the option of avoiding being the first wave of responders. This may be at least partially due to the perception that upper-levels had already experienced growth into their professional identity, despite also likely having more competence. One author noted the altering of "the trajectory of my medical training" and "being asked to step off my planned career path and return to my general medicine foundations [20]." This strongly hints at the perception of an arrest of growth during identity formation and needing to regress to an earlier, less well-differentiated period. Interns and lowerlevels may be perceived as less well-differentiated psychiatrists with less autonomy and were felt to be more malleable to fit the acute needs of programs and hospital systems. Yet it is equally confusing to the role of a PGY-5 who was tasked with helping to organize the COVID-19 response of an entire state, which is perhaps beyond the competence of a pregraduate physician.

\section{Summary and Recommendations}

These issues are intricately related to the perceived role of residents, whether they are "trainees" or "physicians" or both. It may be helpful to acknowledge this dual and sometimes conflicting role, to help trainees and attendings make sense and understand where incidents of Role Confusion may lead to conflict in training programs. Such an understanding may lead to improved communication, problem-solving, and attachment, which would be particularly beneficial during a crisis. Implications include both potentially under- and overestimating the expectations of trainees, and in fact these probably alternate in a way that penalizes residents. This discrepancy existed prior to COVID-19, but the pandemic has only further highlighted this mixed view, which needs to be examined to avoid potentially disastrous consequences.

According to Erickson, the virtue associated with successfully navigating Identity vs. Role Confusion is fidelity, which he defined as "the ability to sustain loyalties freely pledged in spite of the inevitable contradictions of value systems" [25]. Fidelity is marked by loyalty and commitment and allows young people to choose or reject major roles they could assume. Erickson believed that successful resolution of the psychosocial crisis of adulthood - Generativity vs. Stagnationrequires that individuals be capable of exhibiting loyalty and commitment to "occupational choices, various ideologies, and to the nurturance and socialization of younger generations" [25]. Failure to attain this virtue may contribute to "occupational instability" and perhaps - in our language — burnout.

An explicit discussion of these discrepancies may lead to greater understanding and Identity Formation/Cohesion, both for individual residents and for training programs. Recommendations for training programs could include:

- Have honest and transparent discussions about the role of residents

- Acknowledge discrepancies and disparities in role perception that affect residents negatively, particularly during crises 
- Recognize that residents, as a group, require special protections and rights and ensure those protections and rights are granted

- Recognize that residents are growing in autonomy and provide developmentally appropriate independence and autonomy

- Distinguish evaluations based on competence from markers of appropriate professional identity formation

- Treat residents consistently and in line with their appropriate developmental stage

\section{Compliance with Ethical Standards}

Disclosures The author states that there is no conflict of interest.

Disclaimer I am currently a faculty member in a Child Psychiatry training program and thus may have biases related to the content of the paper regarding the role of residents in training programs. The acknowledgement of that potential bias is the point of the paper.

\section{References}

1. Knight ZG. A proposed model of psychodynamic psychotherapy linked to Erik Erikson's eight stages of psychosocial development. Clin Psychol Psychother. 2017;24:1047-58. https://doi.org/10. 1002/cpp.2066.

2. Saunders DE Jr. From practice to academia: a second career in academic medicine. Int J Cardiol. 1984;5:411-6.

3. Long M. Competency-based residency training: the next advance in graduate medical education. Acad Med. 2000;75(12):1178-83. https://doi.org/10.1097/00001888-200012000-00009.

4. Dyrbye LN, Sciolla AF, Dekhtyar M, Rajasekaran S, Allgood JA, Rea M, et al. Medical school strategies to address student wellbeing: a national survey. Acad Med. 2019;94(6):861-8. https:// doi.org/10.1097/ACM.0000000000002611.

5. Lapan C, Boseovski JJ. When peer performance matters: effects of expertise and traits on children's self-evaluation after social comparison. Child Dev. 2017;88(6):1860-72.

6. Twenge JM, Park H. The decline in adult activities among U.S. adolescents, 1976-2016. Child Dev. 2019;90(2):638-54.

7. Scientific American. Extended adolescence: when 25 is the new 18. September 19, 2017; available from https://www. scientificamerican.com/article/extended-adolescence-when-25-isthe-new-181/ [accessed 2 August 2020].

8. Carpenter RO, Spooner J, Arbogast PG, Tarpley JL, Griffin MR, Lomis KD. Work hours restrictions as an ethical dilemma for residents: a descriptive survey of violation types and frequency. Curr Surg. 2006;63(6):448-55. https://doi.org/10.1016/j.cursur.2006.06.003.

9. Kulaylat AN, Qin D, Sun SX, et al. Perceptions of mistreatment among trainees vary at different stages of clinical training. $B M C$ Med Educ. 2017;17(1):14. Published 2017 Jan 14. https://doi.org/ 10.1186/s12909-016-0853-4.

10. UN General Assembly, Convention on the Rights of the Child, 20 November 1989, United Nations, Treaty Series, vol. 1577, p. 3, available at: https://www.refworld.org/docid/3ae6b38fo.html [accessed 2 August 2020].

11. American Medical Association. Residency in a pandemic: How COVID-19 is affecting trainees. 2020; available at https://www. ama-assn.org/residents-students/residency/residency-pandemichow-covid-19-affecting-trainees [accessed 2 August 2020].
12. American Medical Association. Guiding principles to protect resident \& fellow physicians responding to COVID-19.2020; available at https:/www.ama-assn.org/delivering-care/public-health/ guiding-principles-protect-resident-fellow-physicians-responding [accessed 2 August 2020].

13. American Medical Association. AMA issues guidance to protect med students during COVID-19. 2020; available at https:/www. ama-assn.org/press-center/press-releases/ama-issues-guidanceprotect-med-students-during-covid-19 [accessed 2 August 2020].

14. American Medical Association. COVID-19: Residents, fellows need physical and financial protection. 2020; available at https:// www.ama-assn.org/residents-students/resident-student-health/ covid-19-residents-fellows-need-physical-and-financial [accessed 2 August 2020].

15. American Medical Association. COVID-19 volunteer care for health care professionals. 2020; available at https://www.amaassn.org/delivering-care/public-health/covid-19-volunteer-guidehealth-care-professionals [accessed 2 August 2020].

16. American Medical Association. Residents share fears, views on training disruptions during COVID-19. 2020; available at https:// www.ama-assn.org/residents-students/resident-student-health/ residents-share-fears-views-training-disruptions-during [accessed 2 August 2020].

17. In-House. The Epidemic We Don't Talk About: Response to the University of Washington Resident Physician Strike. 2019; available at https://in-housestaff.org/the-epidemic-we-dont-talk-aboutresponse-to-the-university-of-washington-resident-physicianstrike-1572 [accessed 2 August 2020].

18. The Intercept. Medical residents demand COVID-19 hazard pay. 2020; available at https://theintercept.com/2020/04/15/coronavirushospital-medical-residents-hazard-pay/ [accessed 2 August 2020].

19. American Medical Association. How a residency program is protecting its surgeons during COVID-19. 2020; available at https://www.ama-assn.org/residents-students/residency/howresidency-program-protecting-its-surgeons-during-covid-19 [accessed 2 August 2020].

20. Zahid P I'm a psychiatrist, not an emergency room doctor. But I was sent to COVID-19's front lines. USA Today, 2020; accessed from: https://www.usatoday.com/story/opinion/voices/2020/05/28/ doctors-coronavirus-front-lines-medicine-hospital-column/ 5264490002/ [Sep 25 2020].

21. Alberto GE, Rosen BJ, Ho PA. Narrative reflections on the role of psychiatry residents in the early days of the COVID-19 pandemic. Acad Psychiatry. https://doi.org/10.1007/s40596-020-01288-9.

22. Columbia University Department of Psychiatry. COVID-19 - the psychiatry residency response. Accessed from: https://www. columbiapsychiatry.org/education-and-training/psychiatryresidency/covid-19-psychiatry-residency-response. Accessed 26 Sep 2020.

23. Villarin J, Gao N, McCann R. Frontline redeployment of psychiatry residents during the COVID-19 andemic. Psychiatr Serv accepted 22 July 2020. https://ps.psychiatryonline.org/pb-assets/journals/ps/ homepage/Frontline\%20Redeployment $\% 20$ of\%20Psychiatry\% 20Residents\%20During\%20the\%20COVID-19\%20Pandemic.pdf. Accessed 26 Sep 2020.

24. Brauser D Young psychiatrists share stories from the pandemic front lines. Medscape Medical News. June 25, 2020; available at: https:// www.medscape.com/viewarticle/933015\#vp 1 [Sep 26 2020].

25. Markstrom CA, Berman RC, Sabino VM, Turner B. The ego virtue of fidelity as a psychosocial rite of passage in the transition from adolescence to adulthood. Child and Youth Care Forum. 1998;27(5):337-54.

Publisher's Note Springer Nature remains neutral with regard to jurisdictional claims in published maps and institutional affiliations. 